\title{
Modeling the Delivery Routes Carried out by Automated Guided Vehicles when Using the Specific Mathematical Optimization Method
}

https://doi.org/10.1515/eng-2020-0027

Received Sep 11, 2019; accepted Oct 02, 2019

\begin{abstract}
Distribution tasks or transportation problems when using Operations Research methods are mostly addressed by vehicle routing problem methods dealing with an issue of supplying to several nodes, wherein the route begins in a point of origin and, after accomplishing deliveries to individual nodes, vehicle returns to an initial point. Each node can be operated only once, the order of nodes is not determined; however, the major objective is to find the shortest route possible. The aim of this research study is to formulate options to model delivery routes executed by automated guided vehicles in an extensive logistics areal by applying the specific mathematical optimization method. After description of several fundamental aspects and attributes related to automated guided vehicles, distribution tasks and vehicle routing problems which are discussed in introductory chapters, the most important parts containing the specification of Greedy algorithm, as a very useful optimization method for the given purpose, as well as the very models of cargo delivery by automated guided vehicles without / with initial distance optimization are presented.
\end{abstract}

Keywords: distribution task, delivery route, automated guided vehicle, mathematical optimization, Greedy algorithm

\section{Introduction}

An automated guided vehicle (hereinafter as AGV) is a portable robot that follows along marked long lines or wires on the floor, or uses radio waves, vision cameras, magnets, or lasers for navigation. They are most often used

\footnotetext{
*Corresponding Author: Ondrej Stopka: Department of Transport and Logistics, Faculty of Technology, Institute of Technology and Business in České Budějovice, Okružní 517/10, 37001 České Budějovice, Czech Republic; Email: stopka@mail.vstecb.cz
}

in covered and open industrial or logistics objects to transport various sorts of shipments and heavy cargo through or outside these buildings. Over the years, this technology has become more sophisticated, and today, AGVs are mainly laser navigated, e.g. LGV (Laser Guided Vehicle). In an automated process, LGVs are programmed to communicate with other robots to ensure product is moved smoothly through the logistics areal, whether it is being stored for future use or sent directly to shipping areas. Today, the AGVs play an important role in the design of new factories and warehouses, safely moving goods to their rightful destination [1].

The issue of AGV has been addressed in numerous publications. For example, the authors in literature [2] and [3] elaborated case studies dealing with decision makings on path (route) selections of AGVs. This is done through different methods: frequency select mode (wired navigation only), and path select mode (wireless navigation only) or via a magnetic tape on the floor not only to guide the AGV, but also to issue steering commands and speed commands.

Distribution tasks, as formulated by [4], can be classified as the most common linear programming tasks. They include a group of tasks aimed to optimize cargo distribution from the manufacturer (supplier) to the customer (recipient). When addressing the distribution task, usually, the distance traveled between individual places, the quantity of transported products and the requirements of individual customers are known. The homogeneity of goods being transported represents an important condition to solve the distribution task. The author [5] dealt with this issue as well, who stated that thanks to specific properties, it is a type of tasks, for which it is appropriate to use specific methods, which are much more effective to obtain the final solution compared to the universal simplex method, whose use is disadvantageous due to degeneracy and computationally demanding even for not very extensive tasks.

As stated in [6], in the distribution task, a number of suppliers $m$, being allocated into the $D_{i}$ sites where the product is to be transported, are known. Each site has a

ə Open Access. (C) 2020 0. Stopka, published by De Gruyter. (CC) BY This work is licensed under the Creative Commons Attribution 4.0 License 
limited capacity $a_{i}$, which expresses the total transported quantity of the $i$-th supplier. Furthermore, a number of customers $n$, located in the sites $O_{j}$ where products are to be transported, are determined as well. The customer site is characterized by requirements $b_{j}$ (total amount of products being transported to the $j$-th place). The transport volume between the $i$-th supplier and the $i$-th customer is denoted $x_{i j}$. Shipping cost for performed carriage is denoted $c_{i j}$. The aim of the transportation problem (distribution task) is to plan the transport path between source and destination points so that source capacities are not exceeded and all the requirements of the destination sites are met.

The mathematical model of a balanced distribution task contains $m . . . n$ variables $x_{i j}$, which express the transport volume between the $i$-th supplier and the $j$-th customer, and then, it contains $m+n$ own limiting conditions. The limitation $m$ expresses the sum of deliveries from suppliers to customers equal to their capacity. Total sums in lines are equal to relevant capacities. The limitation $n$ expresses the sum of deliveries into destination sites equal to individual requirements. Sums in the columns are equal to the relevant requirements [7].

According to the authors [8-10], the problems belonging to the distribution tasks include in particular: transportation problem, assignment problem, vehicle routing problem (hereinafter as VRP), container transportation problem and the general transportation problem.

The following part of the paper is devoted only to vehicle routing problem and its variants to address the issue of distribution tasks.

\section{Vehicle routing problem}

VRP is defined by the author [11] as follows: Let the set $M$ is given, and for each two elements $x, y$, the number $d(x, y)$ is given, which is called distance between $x$ and $y$. The goal is to specify in which order the salesman (or vehicle) should pass through the elements (nodes) of the $M$ set in order to go through each element just once, and then returns to the point where the journey began while traveling the distance as short as possible. In other words, we search for ordering the $M$ elements into a sequence $x_{1}, \ldots, x_{n}$, which contains each of the $M$ elements just once and the sum of $d\left(x_{1}, x_{2}\right)$ $+d\left(x_{2}, x_{3}\right)+\ldots+d\left(x_{n-1}, x_{n}\right)+d\left(x_{n}, x_{1}\right)$ is as small as possible.

This problem, thus, represents the type of distribution tasks where the delivery of goods to customers is carried out by one or several routing (circular) paths [5]. The objective here is to determine such order of visited places and possibly their inclusion into individual circuits in order that each customer is visited (served) just once and the transport performance (optimization criterion) is minimum. Customer requirements and technological limitations of vehicles must be respected. Depending on the number of circuits needed for the delivery of goods, singlecircuit and multi-circuit tasks can be distinguished [12].

In view of the Graph theory, VRP is a classic transportation problem on the general transport network $G=(V, E)$. The vertex indicated as $V_{0}$ is being the center of the network, and can also be named as a central point or distribution point from which material is distributed to individual delivery points. These points (places requiring an operation) are generally referred to as vertices, $V_{i}, \ldots, V_{n}$, where $n$ denotes a number of vertices $[8,13]$.

Generally for VRP, a requirement for a certain amount of transported cargo in vertices is specified. Cargo is carried by vehicles wherein their maximum capacity is limited, and vehicle's route starts and finishes at the same center $V_{0}$. The task is basically to compile a certain number of circuit routes (routing paths) in order to meet requirements of each customer point, ensure only one operation for each place, and certainly, achieve the smallest possible shipping cost.

As formulated in [14], several specific approaches can be used to solve this type of problem, starting with classical approaches based on graph theory, through mathematical programming, up to unconventional approaches, based on genetic algorithms, ant colonies or heuristic methods.

The authors [15] and [16] state that most of the Operations Research methods within this issue are based on mathematical calculations and algorithms; and to address individual tasks of VRP, multiple specific methods may be applied, particularly exact and heuristic methods. Exact methods include, e.g.:

- the method of linear integer programming;

- brute force method of examining every possible permutation;

- branch-and-bound methods;

- gradual improvement algorithms analogous to techniques of linear programming.

These methods are used to find the optimal solution of the problem using algorithms to solve integer and binary problems, which are based on repeated use of simplex method. Their disadvantage consists in the high computational complexity of larger tasks.

The group of heuristic methods includes, e.g.:

- Greedy algorithm, 
- Nearest Neighbor Algorithm,

- Clarke-Wright method, etc.

Heuristic methods, compared to the exact methods, are much less demanding in terms of calculations and only propose a good solution, but not optimal. However, the resulting solutions have a deviation from the optimal solution of only $2-3 \%$. This declaration is indicated in several publications, for example by authors $[13,17,18]$.

As mentioned above, depending on the number of circuits needed for the delivery of goods, single-circuit and multi-circuit tasks concerning VRP are known.

Sample of the transport network (graph) with vertices and edges regarding the multi-circuit delivery tasks is depicted in following figure (Figure 1).

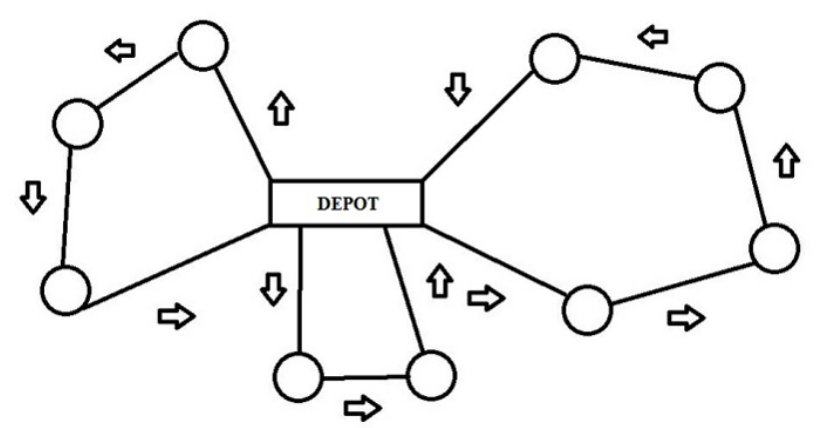

Figure 1: Sample of the multi-circuit delivery task

\section{Data and methods}

This paper is, among other matters, also focused on calculations aimed to apply a particular algorithm that can be used to address distribution tasks of such a nature as well. Typical optimization algorithms basically go through series of simple-choice steps to complete the solution. The algorithm used in this chapter, also called a Greedy algorithm, only consists of multiple steps while the resulting algorithm is efficient and applicable to the given issue. Such tasks can also be called as shuttle transportation problem, i.e. issues consisting in the availability of goods for the customer, or a total waiting time of the customers for goods [19].

Greedy algorithm is, thus, a mathematical process searching for simple, easy-to-implement solutions to complex, multi-step issues by deciding which next step will provide the most obvious benefit. Such algorithms are called greedy, since while the optimal solution to each smaller instance will provide an immediate outcome, the algorithm does not consider the larger problem as a whole. Once a decision has been made, it is never reconsidered [20]. According to [19], Greedy algorithm works by recursively constructing a set of objects from the smallest possible constituent parts. Recursion is an approach to problem solving in which the solution to a particular issue depends on solutions to smaller instances of the same issue. An advantage of using this type of algorithms consists in a fact that solution to smaller instances of the issue can be straightforward and easy to understand. The disadvantage consists in a fact that it is entirely possible that the optimal short-term solution may lead to the worst possible long-term outcome [21].

For purposes of this study, the research chapter will be focused on the optimization and results obtained in terms of operation of specific logistics areal parts (buildings / warehouses / assembly halls) with regard only to perform individual delivery routes from a point of origin to individual facility buildings using the Greedy algorithm.

In our case, the logistics areal (hereinafter as $V_{0}$ ) is located in the southern part of the Czech Republic and, from the inbound logistics site of this object, individual areal parts (hereinafter as $V_{i}$ ), as customers, are to be supplied by particular sorts and types of cargo using AGVs. According to the Greedy algorithm general procedure, the $V_{0}$, as a supplier, must ensure the delivery of goods to selected customers (individual $V_{i}$ in our case), which are sequentially supplied one by one.

The target assignment is to determine the optimal delivery sequence that improves the availability of goods for the individual customers, i.e. to define optimal delivery routes (circuit paths) among individual $V_{i}$ (see Eq. 1).

$$
\sum_{i=1}^{n} t_{i}, \quad i=1,2, \ldots n,
$$

where: $t_{i}$ is the availability (time attribute) of local centers $\left(V_{i}\right)$ while delivering goods from the central point $\left(V_{0}\right)$.

Input data of the task consists of:

- cargo (shipment) distribution between $V_{0}$ and $V_{i}$ by a single AGV returning back to the starting point;

- no cargo amount, vehicle capacities nor customers' requirements are defined;

- constant average vehicle speed of $15 \mathrm{~km} \cdot \mathrm{h}^{-1}$ is specified;

- flat roads' height profile in the logistics areal is maintained;

- no additional waiting time occurs.

Based on above attributes, the customer availability $t_{i}$ given in time units may be replaced by the distance trav- 
Table 1: Calculation of the $d_{i}$ parameter based on distances between $V_{0}$ and $V_{i}$ for single AGV

\begin{tabular}{|c|c|c|c|c|c|c|c|c|c|c|c|c|c|c|c|c|}
\hline$v_{i}$ & 1 & 2 & 3 & 4 & 5 & 6 & 7 & 8 & 9 & 10 & 11 & 12 & 13 & 14 & 15 & 16 \\
\hline$\overline{t_{i}[\mathrm{~km}]}$ & 1.2 & 1.1 & 2.3 & 3.6 & 1.0 & 3.2 & 1.8 & 5.9 & 2.2 & 4.7 & 1.6 & 1.0 & 3.4 & 3.3 & 2.9 & $\overline{5.3}$ \\
\hline$d_{i}[\mathrm{~km}]$ & 1.2 & 3.5 & 6.9 & 12.8 & 17.4 & 21.6 & 26.6 & 34.3 & 42.4 & 49.3 & 55.6 & 58.2 & 62.6 & 69.3 & 75.5 & 83.7 \\
\hline
\end{tabular}

Table 2: Calculation of the $d_{i}$ parameter based on distances between $V_{0}$ and $V_{i}$ for two AGVs

\begin{tabular}{|c|c|c|c|c|c|c|c|c|c|c|c|c|c|c|c|c|}
\hline$V_{i}$ & 1 & 2 & 3 & 4 & 5 & 6 & 7 & 8 & 9 & 10 & 11 & 12 & 13 & 14 & 15 & 16 \\
\hline$t_{i}[\mathrm{~km}]$ & 1.2 & 1.1 & 2.3 & 3.6 & 1.0 & 3.2 & 1.8 & 5.9 & 2.2 & 4.7 & 1.6 & 1.0 & 3.4 & 3.3 & 2.9 & 5.3 \\
\hline$A G V$ & 1. & 2. & 1. & 2. & 1. & 2. & 1. & 2. & 1. & 2. & 1. & 2. & 1. & 2. & 1. & 2 \\
\hline$d_{i}[\mathrm{~km}]$ & 1.2 & 1.1 & 4.7 & 5.8 & 8.0 & 12.6 & 10.8 & 21.7 & 14.8 & 32.3 & 18.6 & 38.0 & 23.6 & 42.3 & 29.9 & 50.9 \\
\hline
\end{tabular}

Table 3: Calculation of the $d_{i}$ parameter based on distances between $V_{0}$ and $V_{i}$ for four AGVs

\begin{tabular}{|c|c|c|c|c|c|c|c|c|c|c|c|c|c|c|c|c|}
\hline$V_{i}$ & 1 & 2 & 3 & 4 & 5 & 6 & 7 & 8 & 9 & 10 & 11 & 12 & 13 & 14 & 15 & 16 \\
\hline$t_{i}[\mathrm{~km}]$ & 1.2 & 1.1 & 2.3 & 3.6 & 1.0 & 3.2 & 1.8 & 5.9 & 2.2 & 4.7 & 1.6 & 1.0 & 3.4 & 3.3 & 2.9 & 5.3 \\
\hline$A G V$ & 1. & 2. & 3. & 4. & 1. & 2. & 3. & 4. & 1. & 2. & 3. & 4. & 1. & 2. & 3. & 4. \\
\hline$d_{i}[\mathrm{~km}]$ & 1.2 & 1.1 & 2.3 & 3.6 & 3.4 & 5.4 & 6.4 & 13.1 & 6.6 & 13.3 & 9.8 & 20.0 & 12.2 & 21.3 & 14.3 & 26.3 \\
\hline
\end{tabular}

Table 4: Calculation of the $d_{i}$ parameter based on distances between $V_{0}$ and $V_{i}$ for six AGVs

\begin{tabular}{|c|c|c|c|c|c|c|c|c|c|c|c|c|c|c|c|c|}
\hline$V_{i}$ & 1 & 2 & 3 & 4 & 5 & 6 & 7 & 8 & 9 & 10 & 11 & 12 & 13 & 14 & 15 & 16 \\
\hline$\overline{t_{i}[\mathrm{~km}]}$ & 1.2 & 1.1 & 2.3 & 3.6 & 1.0 & 3.2 & 1.8 & 5.9 & 2.2 & 4.7 & 1.6 & 1.0 & 3.4 & 3.3 & 2.9 & 5.3 \\
\hline$A G V$ & 1. & 2. & 3. & 4. & 5. & 6. & 1. & 2. & 3. & 4. & 5. & 6. & 1. & 2. & 3. & 4. \\
\hline$d_{i}[\mathrm{~km}]$ & 1.2 & 1.1 & 2.3 & 3.6 & 1.0 & 3.2 & 4.2 & 8.1 & 6.8 & 11.9 & 3.6 & 7.4 & 9.4 & 17.3 & 11.9 & 21.9 \\
\hline
\end{tabular}

eled $\left(d_{i}\right)$ from the central depot to the local centers $V_{i}$ given in $\mathrm{km}$ according to equation 2 [22].

$$
\begin{aligned}
& t_{i}=d_{i} \\
& \cdots \\
& t_{1}=d_{1} \\
& t_{2}=t_{1}+\left(d_{1}+d_{2}\right)=2 d_{1}+d_{2} \\
& \ldots \\
& t_{n}=t_{n-1}+\left(d_{n-1}+d_{n}\right)=2 d_{1}+d_{2}+, \ldots,+2 d_{n-1}+d_{n}
\end{aligned}
$$

\section{Results and Discussion}

The following subchapters are focused on comparative analysis of results obtained prior to and after the optimization based on distance traveled from the central point $V_{0}$ to individual customers $V_{i}$ using Greedy algorithm. Sorting customers to the delivery sequence $V_{1}-V_{16}$ is firstly made by random selection for deliveries without distance optimization. This procedure is applied due to the aim to find out the overall driving performance and individual distances traveled to each customer in order to provide best availability of goods to customers [23, 24].

\subsection{Model of cargo delivery by AGV without initial distance optimization}

In terms of delivery routes, logistics areal objects $\left(V_{1}-V_{16}\right)$ are firstly sorted without optimization, and are operated by random selection. Since it is about improving the availability of goods for the customer $\sum_{i=1}^{n} d_{i}$, it is necessary to use some mathematical apparatus to achieve the best cargo availability to the customer (given in kilometers) [25]. In order to substitute the distance $d_{i}$ into the equation (Eq. 2), it is needed to identify the real distance from $V_{0}$ to individual facility parts. These distance as well as resulting distance values of calculating the parameter $d_{i}$ as a basis to optimize delivery activities to $\left(V_{i}\right)$ from an inbound site $\left(V_{0}\right)$ are summarized in Table 1.

The delivery sequence prior to the optimization of delivery routes is as follows $V_{i}(1,2,3,4,5,6,7,8,9,10,11$, $12,13,14,15,16)$ and the overall driving performance using a single AGV to operate individual logistics areal building (Vi) is $\sum_{i=1}^{n} d_{i}=620.9 \mathrm{~km}$.

Following tables (Table 2 - 5) contain four cases of customers' operation in terms of number of AGVs while gradually two, four, six and eight vehicles are taken into account for individual calculations. 
Table 5: Calculation of the $d_{i}$ parameter based on distances between $V_{0}$ and $V_{i}$ for eight AGV

\begin{tabular}{|c|c|c|c|c|c|c|c|c|c|c|c|c|c|c|c|c|}
\hline$V_{i}$ & 1 & 2 & 3 & 4 & 5 & 6 & 7 & 8 & 9 & 10 & 11 & 12 & 13 & 14 & 15 & 16 \\
\hline$t_{i}[\mathrm{~km}]$ & 1.2 & 1.1 & 2.3 & 3.6 & 1.0 & 3.2 & 1.8 & 5.9 & 2.2 & 4.7 & 1.6 & 1.0 & 3.4 & 3.3 & 2.9 & 5.3 \\
\hline$A G V$ & 1. & 2. & 3. & 4. & 5. & 6. & 7. & 8. & 1. & 2. & 3. & 4. & 5. & 6. & 7. & 8. \\
\hline$d_{i}[\mathrm{~km}]$ & 1.2 & 1.1 & 2.3 & 3.6 & 1.0 & 3.2 & 1.8 & 5.9 & 4.6 & 6.9 & 6.2 & 8.2 & 5.4 & 9.7 & 6.5 & 17.1 \\
\hline
\end{tabular}

Table 6: Calculation of the $d p_{i}$ parameter based on sorted distances between $V_{0}$ and $V_{i}$ for one AGV

\begin{tabular}{|c|c|c|c|c|c|c|c|c|c|c|c|c|c|c|c|c|}
\hline$V_{i}$ & 5 & 12 & 2 & 1 & 11 & 7 & 9 & 3 & 15 & 6 & 14 & 13 & 4 & 10 & 16 & 8 \\
\hline$t_{i}[\mathrm{~km}]$ & 1.0 & 1.0 & 1.1 & 1.2 & 1.6 & 1.8 & 2.2 & 2.3 & 2.9 & 3.2 & 3.3 & 3.4 & 3.6 & 4.7 & 5.3 & 5.9 \\
\hline$d p_{i}[\mathrm{~km}]$ & 1.0 & 3.0 & 5.1 & 7.4 & 10.2 & 13.6 & 17.6 & 22.1 & 27.3 & 33.4 & 39.9 & 46.6 & 53.6 & 61.9 & 71.9 & 83.1 \\
\hline
\end{tabular}

\subsection{Model of cargo delivery by AGV with initial distance optimization using Greedy algorithm}

The outcomes of this subchapter are aimed at optimizing the operation of $V_{i}$ from $V_{0}$ based on distances by applying Greedy algorithm to determine the best availability of goods for customers. Optimization is conducted for five cases of logistics areal supply in terms of number of AGV. One, two, four, six and eight vehicles are taken into consideration. The optimization results, and thus the individual delivery models with distance optimization are then compared with the original delivery model without distance optimization when using one to eight AGVs [26, 27].

\subsubsection{Model of cargo delivery using one AGV}

The first step of the optimization is to sort the distance traveled $\left(t_{i}\right)$ between the central point $\left(V_{0}\right)$ and individual customers $\left(V_{i}\right)$ from the smallest to the highest value according to the greedy principle (see Table 6). Based on these known parameters, the overall availability of goods $\left(d p_{i}\right)$ can be expressed by an objective function (Eq. 3):

$$
\sum_{i=1}^{n} d p_{i}=(2 n-1) d_{i}+(2 n-3) d_{2}+\ldots+3 d_{n-1}+d_{n}
$$

Since $n$ is given, it is necessary to assign the smallest distance for $d_{1}$, the second smallest distance for $d_{2}$, and the highest distance for $d_{n}$ to minimize the availability of goods to customers.

The delivery sequence after the optimization of delivery routes is as follows $V_{i}(5,12,2,1,11,7,9,3,15,6,14,13$, 4, $10,16,8)$ and the overall driving performance using a single AGV to operate individual center parts $(\mathrm{Vi})$ is $\sum_{i=1}^{n} d p_{i}$ $=497.7 \mathrm{~km}$.

The following figure (see Figure 2) graphically depicts the increase in driving performance prior to and after the

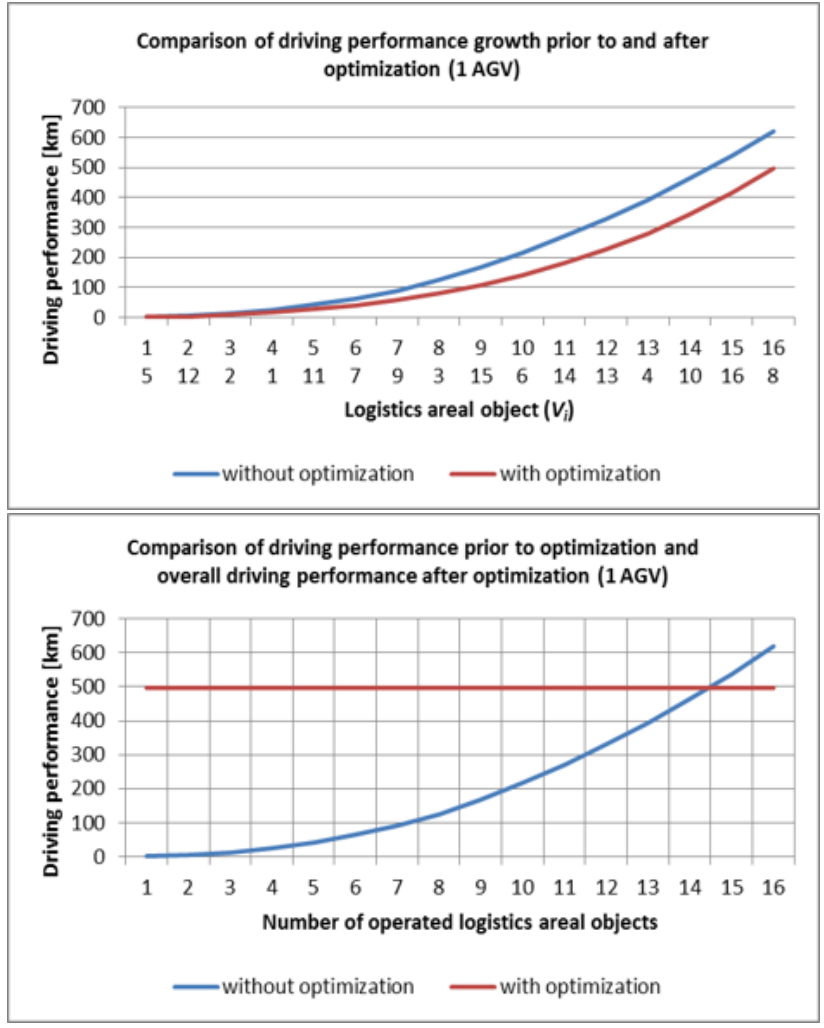

Figure 2: Graphical representation of driving performance prior to and after the distance optimization when using single AGV

distance optimization by implementing Greedy algorithm when using single AGV. Obviously, as a result of optimization, driving performance increases with the number of operated centers slower than prior to optimization (left graph), as well as overall driving performance is lower compared to the original state (right graph).

At the top of the $x$-axis of the left graph, the description of customers' random delivery sequence prior to the distance optimization of operation is indicated, and at the bottom of the $x$-axis, the new delivery sequence after the optimization when applying Greedy algorithm is defined. 
Table 7: The $d p_{i}$ parameter based on sorted distances between $V_{0}$ and $V_{i}$ for two delivery vehicles

\begin{tabular}{|c|c|c|c|c|c|c|c|c|c|c|c|c|c|c|c|c|}
\hline$V_{i}$ & 5 & 12 & 2 & 1 & 11 & 7 & 9 & 3 & 15 & 6 & 14 & 13 & 4 & 10 & 16 & 8 \\
\hline$t_{i}[\mathrm{~km}]$ & 1.0 & 1.0 & 1.1 & 1.2 & 1.6 & 1.8 & 2.2 & 2.3 & 2.9 & 3.2 & 3.3 & 3.4 & 3.6 & 4.7 & 5.3 & 5.9 \\
\hline$A G V$ & 1. & 2. & 1. & 2. & 1. & 2. & 1. & 2. & 1. & 2. & 1. & 2. & 1. & 2. & 1. & 2. \\
\hline$d p_{i}[\mathrm{~km}]$ & 1.0 & 1.0 & 3.1 & 3.2 & 5.8 & 6.2 & 9.6 & 10.3 & 14.7 & 15.8 & 20.9 & 22.4 & 27.8 & 30.5 & 36.7 & 41.1 \\
\hline
\end{tabular}

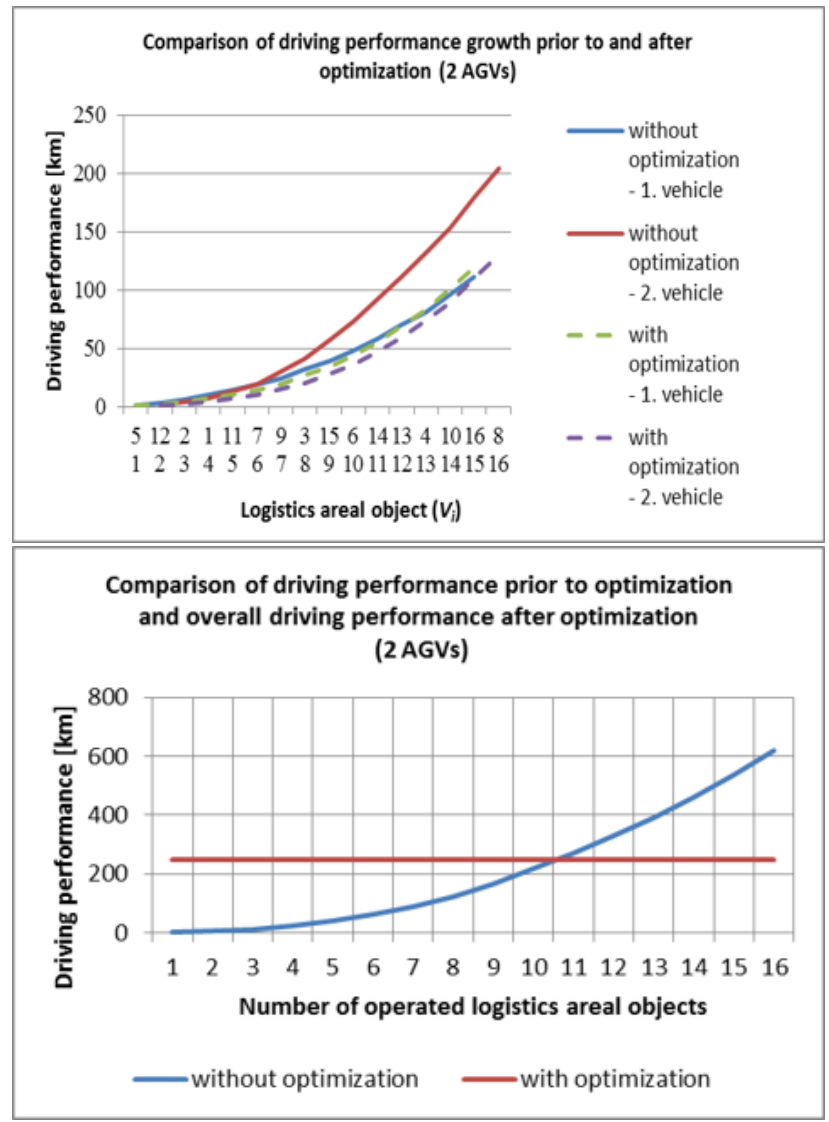

Figure 3: Graphical representation of driving performance prior to and after the distance optimization when using two AGVs

From the graph on the right, when using a single AGV, it is clear that the optimized overall driving performance is already achieved after the operation of 14 th customer prior to the optimization. In a same way, calculations and graphical courses are made in the graphs below (Figure $3-6$ ).

\subsubsection{Model of cargo delivery using two AGVs}

The calculation of the $d p_{i}$ parameter based on the sorted distances between $V_{0}$ and $V_{i}$ when delivering by two vehicles is summarized in Table 7.

The delivery sequence to customers after the optimization of delivery routes when using two AGVs is as follows $V_{i}$ (veh. 1 - 5, 2, 11, 9, 15, 14, 4, 16; veh. 2 - 12, 1, 7, 3, 6, 13, 10,

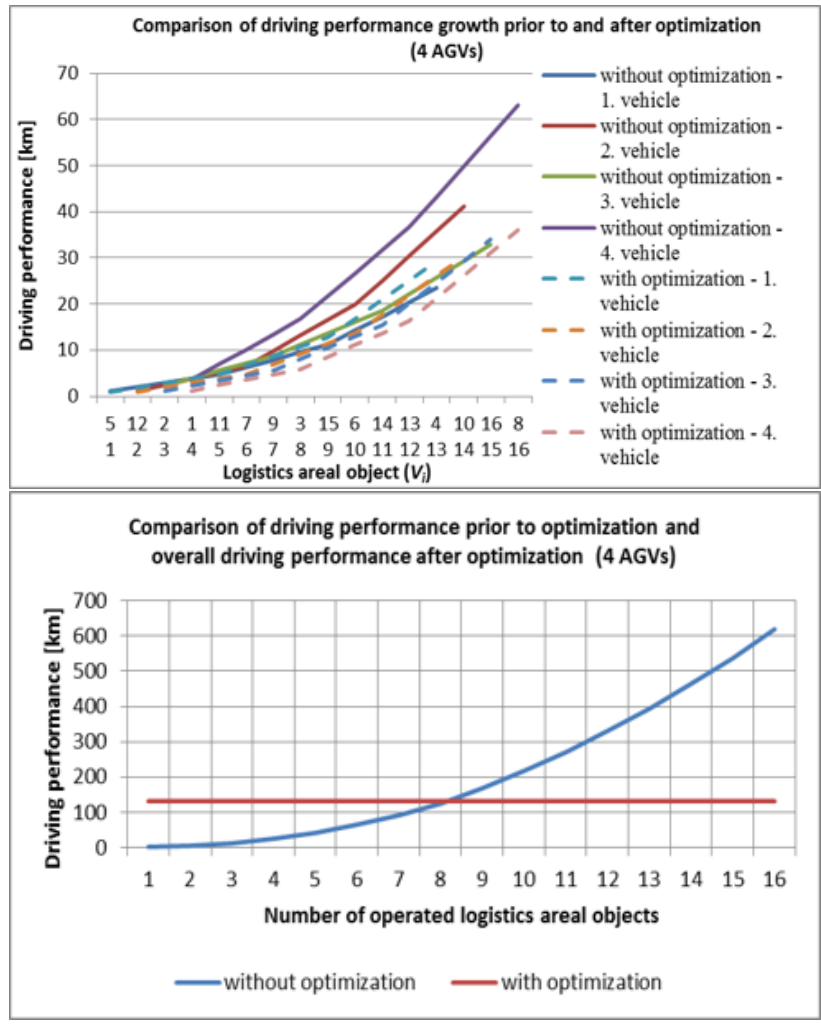

Figure 4: Course of driving performance prior to and after the distance optimization when using four AGVs

8) and the overall driving performance to operate individual buildings $(V i)$ is $\sum_{i=1}^{n} d p_{i}=250.1 \mathrm{~km}$ (veh. $1=119.6 \mathrm{~km}$ and veh. $2=130.5$ ).

Figure 3, as follows, illustrates the increase in driving performance prior to and after the distance optimization applying Greedy algorithm when using two AGVs.

\subsubsection{Model of cargo delivery using four AGVs}

The calculation of the $d p_{i}$ parameter based on the sorted distances between $V_{0}$ and $V_{i}$ when using four delivery vehicles is presented in Table 8.

The delivery sequence to customers after the optimization of delivery routes when using four AGVs is as follows $V_{i}$ (veh. 1 - 5, 11, 15, 4; veh. 2 - 12, 7, 6, 10; veh. 3 - 2, 9, 14, 16 ; veh. $4-1,3,13,8$ ) and the overall driving performance 
Table 8: The $d p_{i}$ parameter based on sorted distances between $V_{0}$ and $V_{i}$ for four AGVs

\begin{tabular}{|c|c|c|c|c|c|c|c|c|c|c|c|c|c|c|c|c|}
\hline$V_{i}$ & 5 & 12 & 2 & 1 & 11 & 7 & 9 & 3 & 15 & 6 & 14 & 13 & 4 & 10 & 16 & 8 \\
\hline$t_{i}[\mathrm{~km}]$ & 1.0 & 1.0 & 1.1 & 1.2 & 1.6 & 1.8 & 2.2 & 2.3 & 2.9 & 3.2 & 3.3 & 3.4 & 3.6 & 4.7 & 5.3 & 5.9 \\
\hline$A G V$ & 1. & 2. & 3. & 4. & 1. & 2. & 3. & 4. & 1. & 2. & 3. & 4. & 1. & 2. & 3. & 4. \\
\hline$d p_{i}[\mathrm{~km}]$ & 1.0 & 1.0 & 1.1 & 1.2 & 3.6 & 3.8 & 4.4 & 4.7 & 8.1 & 8.8 & 9.9 & 10.4 & 16.6 & 16.7 & 18.5 & 19.7 \\
\hline
\end{tabular}

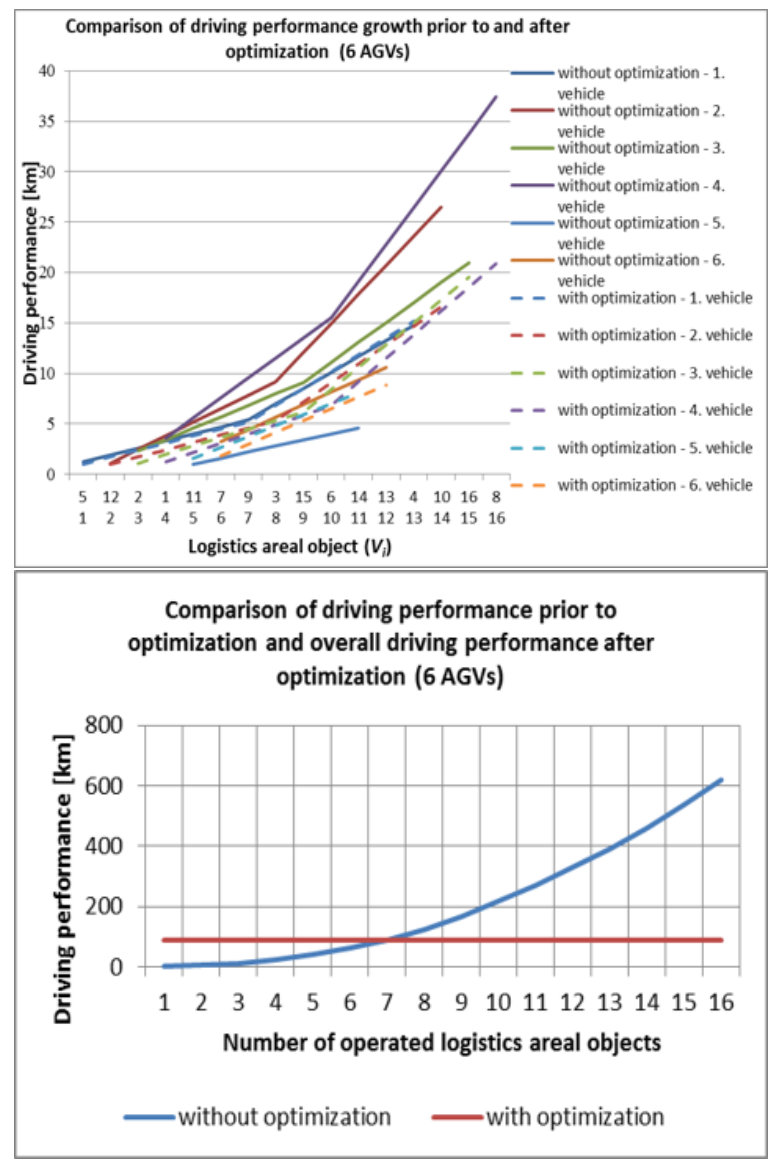

Figure 5: Course of driving performance prior to and after the distance optimization when using six AGVs

to operate individual buildings $(\mathrm{Vi})$ is $\sum_{i=1}^{n} d p_{i}=127.5 \mathrm{~km}$ (veh. $1=27.3 \mathrm{~km}$; veh. $2=30.3 \mathrm{~km}$; veh. $3=33.9 \mathrm{~km}$ and veh. $4=36.0 \mathrm{~km})$.

The following figure (see Figure 4) illustrates the increase in driving performance prior to and after the distance optimization by applying Greedy algorithm when using four AGVs.

\subsubsection{Model of cargo delivery using six vehicles}

The calculation of the $d p_{i}$ parameter based on the sorted distances between $V_{0}$ and $V_{i}$ when using six delivery vehicles is presented in following Table 9.

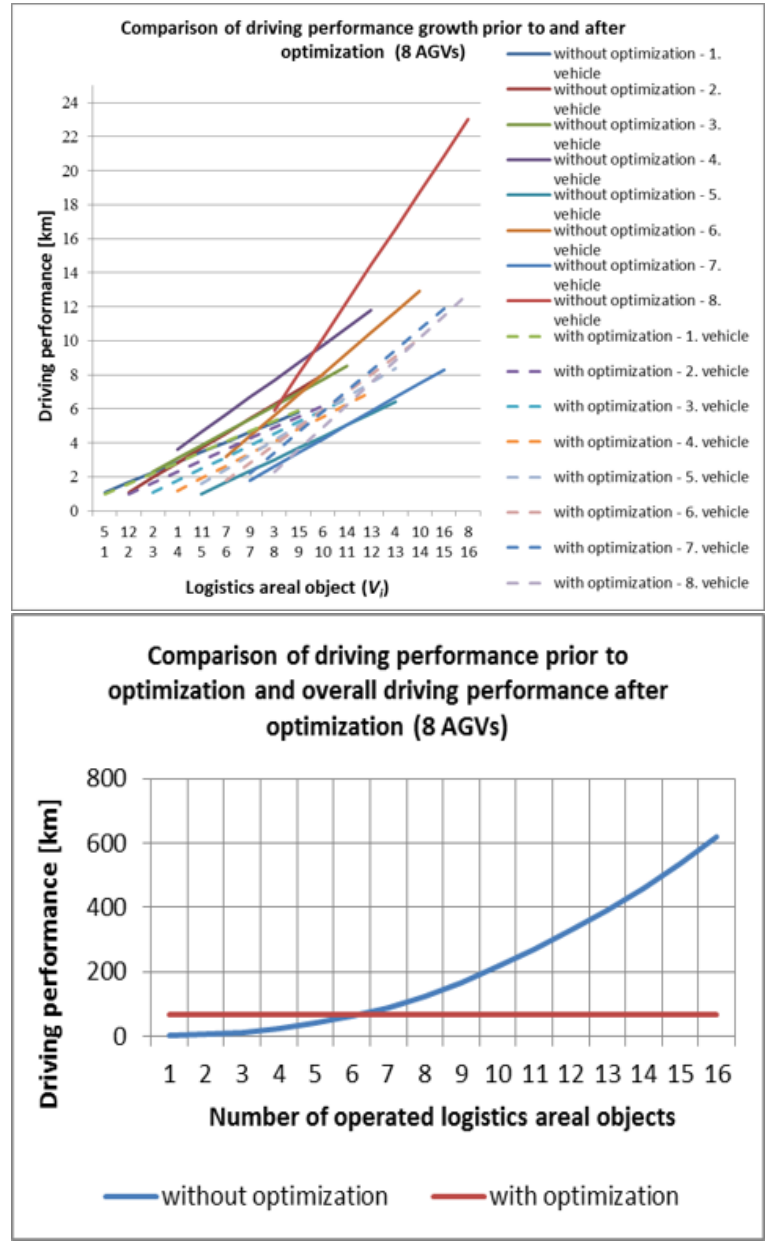

Figure 6: Graphical overview of driving performance prior to and after the distance optimization when using eight AGVs

Following the Table 9, the delivery sequence to customers after the optimization of delivery routes when using six vehicles is as follows $V_{i}$ (veh. 1 - 5, 9, 4; veh. 2 - 12, 3, 10; veh. 3 - 2, 15, 16; veh. 4 - 1, 6, 8; veh. 5 - 11, 14; veh. 6 $7,13)$ and the overall driving performance while operating individual centers $(V i)$ is $\sum_{i=1}^{n} d p_{i}=89.1 \mathrm{~km}$ (veh. $1=15.2$ $\mathrm{km}$; veh. $2=16.6 \mathrm{~km}$; veh. $3=19.5 \mathrm{~km}$ and veh. $4=20.9 \mathrm{~km}$; veh. $5=8.1 \mathrm{~km}$ and veh. $6=8.8 \mathrm{~km}$ ).

The following figure (see Figure 5) illustrates the increase in driving performance prior to and after the distance optimization by utilizing Greedy algorithm when using six delivery vehicles. 
Table 9: The dpi parameter based on sorted distances between $V_{0}$ and $V i$ for six AGVs

\begin{tabular}{|c|c|c|c|c|c|c|c|c|c|c|c|c|c|c|c|c|}
\hline$v_{i}$ & 5 & 12 & 2 & 1 & 11 & 7 & 9 & 3 & 15 & 6 & 14 & 13 & 4 & 10 & 16 & 8 \\
\hline$t_{i}[\mathrm{~km}]$ & 1.0 & 1.0 & 1.1 & 1.2 & 1.6 & 1.8 & 2.2 & 2.3 & 2.9 & 3.2 & 3.3 & 3.4 & 3.6 & 4.7 & 5.3 & 5.9 \\
\hline Veh. & 1. & 2. & 3. & 4. & 5. & 6. & 1. & 2. & 3. & 4. & 5. & 6. & 1. & 2. & 3. & 4. \\
\hline$d p_{i}[\mathrm{~km}]$ & 1.0 & 1.0 & 1.1 & 1.2 & 1.6 & 1.8 & 4.2 & 4.3 & 5.1 & 5.6 & 6.5 & 7.0 & 10.0 & 11.3 & 13.3 & 14.1 \\
\hline
\end{tabular}

Table 10: The dpi parameter based on sorted distances between $V_{0}$ and $V i$ for eight delivery vehicles

\begin{tabular}{|c|c|c|c|c|c|c|c|c|c|c|c|c|c|c|c|c|}
\hline$V_{i}$ & 5 & 12 & 2 & 1 & 11 & 7 & 9 & 3 & 15 & 6 & 14 & 13 & 4 & 10 & 16 & 8 \\
\hline$t_{i}[\mathrm{~km}]$ & 1.0 & 1.0 & 1.1 & 1.2 & 1.6 & 1.8 & 2.2 & 2.3 & 2.9 & 3.2 & 3.3 & 3.4 & 3.6 & 4.7 & 5.3 & 5.9 \\
\hline Veh. & 1. & 2. & 3. & 4. & 5. & 6. & 7. & 8. & 1. & 2. & 3. & 4. & 5. & 6. & 7. & 8. \\
\hline$d p_{i}[\mathrm{~km}]$ & 1.0 & 1.0 & 1.1 & 1.2 & 1.6 & 1.8 & 2.2 & 2.3 & 4.9 & 5.2 & 5.5 & 5.8 & 6.8 & 8.3 & 9.7 & 10.5 \\
\hline
\end{tabular}

\subsubsection{Model of goods delivery using eight AGVs}

The calculation of the $d p_{i}$ parameter based on the sorted distances between $V_{0}$ and $V_{i}$ when using eight delivery vehicles is summarized in Table 10 as follows.

The delivery sequence to customers after the optimization of delivery routes when using eight AGVs is as follows $V_{i}$ (veh. 1 - 5, 15; veh. 2 - 12, 6; veh. 3 - 2, 14; veh. 4 - 1, 13; veh. 5 - 11, 4; veh. 6 - 7, 10; veh. 7 - 9, 16; veh. 8 - 3,8) and the overall driving performance to operate individual centers (Vi) is $\sum_{i=1}^{n} d p_{i}=68.9 \mathrm{~km}$ (veh. $1=5.9 \mathrm{~km}$; veh. $2=6.2 \mathrm{~km}$; veh. $3=6.6 \mathrm{~km}$ and veh. $4=7.0 \mathrm{~km}$; veh. $5=8.4 \mathrm{~km}$; veh. 6 $=10.1 \mathrm{~km}$; veh. $7=11.9 \mathrm{~km}$ and veh. $8=12.8 \mathrm{~km}$ ).

The following figure (see Figure 6) depicts the increase in driving performance prior to and after the distance optimization by applying Greedy algorithm when using eight AGVs.

Based on the above procedures and calculations, various statements and proposals can be made. According to the distance optimization when applying Greedy algorithm, operator of the logistics areal can choose and determine the method of cargo deliveries to individual areal objects (buildings) depending on the number of AGVs to be deployed [28]. The only thing that matters is the number of available AGVs to be used, and possibly the preferential point of view of the operator. One way or another, in each of five optimization scenarios, significant distance as well as costs savings may be achieved [29].

\section{Conclusion}

As stated above, the major objective of this study was to outline an option for modeling individual delivery routes performed by automated guided vehicles in particular large logistics facility by using the specific optimiza- tion method; namely, Greedy algorithm was implemented. Specifically, modeling the several scenarios of cargo delivery for a different number of automated guided vehicles without / with initial distance optimization was performed. The logistics plant is located in the southern part of the Czech Republic and, from the inbound site of this facility, individual object buildings were supplied by particular sorts and types of cargo using AGVs.

Although sometimes, Greedy algorithm fails to search for the overall optimal solution, since it does not take into consideration all the data, whereby the selection performed by Greedy algorithm may depend on choices being made so far, and thus it is not aware of future selections it may perform, by applying the simple Greedy algorithm method, the significant distance or time savings can be achieved after all. Following the main findings, hence, it was confirmed that Greedy algorithm appears to be an appropriate and effective technique to be used for the purpose of this manuscript in order to determine the optimal (near optimal) order of customers' supply by automated guided vehicles.

Based on the statements above as well as a brief literature review elaborated in first two chapters, it can be concluded that such a modeling has not been carried out before and published yet and may, therefore, be referred as a new / innovative view of techniques for addressing the delivery routes performed by given means of transport. Possibly, as for the next step in this context in the future, it may cover discussing the financial issue and economic calculations concerning the models of cargo delivery.

Acknowledgement: This manuscript was supported within solving the research project entitled "Autonomous mobility in the context of regional development LTC19009" of the INTER-EXCELLENCE program, the VES 19 INTERCOST subprogram. 


\section{References}

[1] Fragapane G.I., Bertnum A.B., Hvolby H.H., Strandhagen J.O., Material Distribution and Transportation in a Norwegian Hospital: A Case Study, In: 16th IFAC Symposium on Information Control Problems in Manufacturing (INCOM), (Bergamo, Italy), June 11-13. IFAC Papersonline, 2018, 51(11), 352-357. DOI: 10.1016/j.ifacol.2018.08.316

[2] Cho J.H., Kim Y.T., Design of Autonomous Logistics Transportation Robot System with Fork-Type Lifter, International Journal of Fuzzy Logic and Intelligent Systems, 2017, 17(3), 177-186. DOI: 10.5391/IJFIS.2017.17.3.177

[3] Zhao J., Fei L., The Optimal Path Planning for Warehouse Logistics AGV Based on Ant Colony Algorithm, In: International Conference on Electrical and Control Engineering (ICECE), Guilin, China, April 18-19, 2015, 180-185

[4] Fiala P., et al., Operační výzkum - nové trendy. 1st ed., Prague: Professional Publishing, Czech Republic, 2010, 239 p. ISBN97880-7431-036-2. (in Czech)

[5] Holoubek J., Ekonomicko-matematické metody, Brno: Mendel University of Agriculture and Forestry, Czech Republic, 2006. ISBN 80-7157-970-X. (in Czech)

[6] Kampf R., Hlatka M., Savin G., Proposal for optimizing specific distribution routes by means of the specific method of operational analysis, Communications - Scientific Letters of the University of Zilina, 2017, 19(2), 133-138

[7] Fábry J., Matematické modelování. 1st ed., Prague: Professional Publishing, Czech Republic, 2011. ISBN 978-80-7431-066-9. (in Czech)

[8] Jablonský J., Operační výzkum: kvantitativní modely pro ekonomické rozhodování. Ed. 3, Prague: Professional Publishing, Czech Republic, 2007, 323 p. ISBN 978-80-86946-44-3. (in Czech)

[9] Bu L., van Duin J.H.R., Wiegmans B., Luo Z., Yin C., Selection of City Distribution Locations in Urbanized Areas, Procedia - Social and Behavioral Sciences, 2012, 39, 556-567. DOI: 10.1016/j.sbspro.2012.03.130

[10] Gonzalez-Feliu J., Vehicle routing in multi-echelon distribution systems with cross-docking: A systematic lexical-metanarrative analysis, Computer and Information Science, 2013, 6(3). DOI: $10.5539 /$ cis.v6n3p28

[11] Kruskal J.B.Jr., On the Shortest Spanning Subtree of a Graph and the Traveling Salesman Problem, Proceedings of the American Mathematical Society, 1957, 7, 48-50

[12] Yang J., Shi X., Marchese M., Liang Y., An ant colony optimization method for generalized TSP problem, Progress in Natural Science, 2008, 18(11), 1417-1422

[13] Chovancová M., Klapita V., Modeling the Supply Process Using the Application of Selected Methods of Operational Analysis, Open Engineering, 2017, 7(1), 50-54. DOI: 10.1515/eng-20170009

[14] Teichmann D., Dorda M., Úloha obchodního cestujícího s částečně řízenou obsluhou vrcholů, Perner's Contacts, 2011, 6, 375-376. (in Czech)

[15] Volek J., Linda B., Teorie grafů: aplikace v dopravě a veřejné správě. 1st ed., Pardubice: University of Pardubice, Czech Republic, 2012, 192 p. ISBN 978-80-7395-225-9. (in Czech)
[16] Burdová J., Heuristické a metaheuristické metody řešení úlohy obchodního cestujícího. Diploma thesis, Prague, Vysoká škola ekonomická v Praze, Czech Republic, 2011. (in Czech)

[17] Široký J., Slivoně M., The optimization of pick-up and delivery of small consignments, Perner's Contacts, 2010, 5(1), 255-269

[18] Tokgöz E., Alwazzi S., Trafalis T.B., A heuristic algorithm to solve the single-facility location routing problem on Riemannian surfaces, Computational Management Science, 2014, 19 p. DOI:10.1007/s10287-014-0226-6

[19] Yujun Z., Chuanqing X., Jinyun X.A., Simple greedy algorithm for a class of shuttle transportation problems, Optimization letters, 2009, 3(4), 491-497

[20] Carvalho J., Vieira D., Trinta F., Greedy multi-cloud selection approach to deploy an application based on microservices, In: 27th Euromicro International Conference on Parallel, Distributed and Network-Based Processing, PDP 2019, Pavia, Italy, 13-15 February 2019, Code 146395, 93-100. DOI: 10.1109/EMPDP.2019.8671608

[21] Yuan L., Huang R., Han L., Zhou M., A parking guidance algorithm based on time-optimal dynamic sorting for underground parking, In: 26th International Conference on Geoinformatics, Geoinformatics 2018, Kunming, China, 28-30 June 2018, Code 143470. DOI: 10.1109/GEOINFORMATICS.2018.8557079

[22] Smirnov A.V., The shortest path problem for a multiple graph, Automatic Control and Computer Sciences, 2018, 52(7), 625-633. DOI: $10.3103 / \mathrm{S} 0146411618070234$

[23] Phan A.T., Nguyen T.D., Pham Q.D., Traveling salesman problem with multiple drones, In: 9th International Symposium on Information and Communication Technology, SolCT 2018, Da Nang, Viet Nam, 6-7 December 2018, Code 143217, 46-53. DOI: 10.1145/3287921.3287932

[24] Bartuska L., Hanzl J., Lizbetinova L., Possibilities of using the data for planning the cycling infrastructure, Procedia engineering, 2016, 161, 282-289. DOI: 10.1016/j.proeng.2016.08.555

[25] Šimková I., Konečný V., Kapusta J., The definition of the freight road transport criteria, Logi - Scientific Journal on Transport and Logistics, 2015, 6(1), 120-129. ISSN 1804-3216

[26] Fedorko G., Molnar V., Vasil M., Hanzl J., Application of the Tecnomatix Plant Simulation Program to Modelling the Handling of Ocean Containers using the AGV System, Nase More, 2018, 65(4), 230-236. DOI: 10.17818/NM/2018/4SI.12

[27] Kubasakova I., Kubanova J., Poliakova B., Modelling of Opened System in the Road Freight Transport and its Impact on the System Characteristics, In: 19th International Scientific Conference on Transport Means, 2015, 405-409, Kaunas, Lithuania, October 22-23

[28] Hlatka M., Bartuska L., Lizbetin J., Application of the Vogel Approximation Method to Reduce Transport-logistics Processes, 2017, MATEC Web of Conferences, 134, Article no. 00019, In: 18th International Scientific Conference on LOGI, Ceske Budejovice, Czech Republic, October 19, 2017. DOI: 10.1051/matecconf/201713400019

[29] Karoonsoontawong A., Kobkiattawin O., Xie C., Efficient insertion heuristic algorithms for multi-trip inventory routing problem with time windows, shift time limits and variable delivery time, Networks and Spatial Economics, 2017, 1-49. DOI: 10.1007/s11067017-9369-7 